\title{
Platinum sensitivity and CD133 expression as risk and prognostic predictors of central nervous system metastases in patients with epithelial ovarian cancer
}

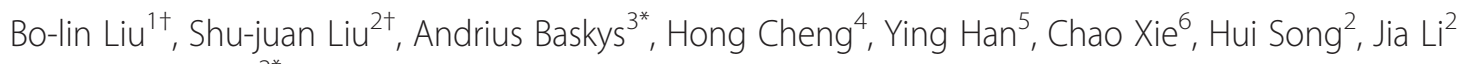
and Xiao-yan Xin ${ }^{2^{*}}$

\begin{abstract}
Background: To characterize prognostic and risk factors of central nervous system (CNS) metastases in patients with epithelial ovarian cancer (EOC).

Methods: A retrospective analysis of Xijing Hospital electronic medical records was conducted to identify patients with pathologically confirmed EOC and CNS metastases. In addition to patient demographics, tumor pathology, treatment regimens, and clinical outcomes, we compared putative cancer stem cell marker CD133 expression patterns in primary and metastatic lesions as well as in recurrent EOC with and without CNS metastases.
\end{abstract}

Results: Among 1366 patients with EOC, metastatic CNS lesions were present in 29 (2.1\%) cases. CD133 expression in primary tumor was the only independent risk factor for CNS metastases; whilst the extent of surgical resection of primary EOC and platinum resistance were two independent factors significantly associated with time to CNS metastases. Absence of CD133 expression in primary tumors was significantly associated with high platinum sensitivity in both patient groups with and without CNS metastases. Platinum resistance and CD133 cluster formation in CNS metastases were associated with decreased survival, while multimodal therapy including stereotactic radiosurgery (SRS) for CNS metastases was associated with increased survival following the diagnosis of CNS metastases.

Conclusions: These data suggest that there exist a positive association between CD133 expression in primary EOC, platinum resistance and the increased risk of CNS metastases, as well as a less favorable prognosis of EOC. The absence of CD133 clusters and use of multimodal therapy including SRS could improve the outcome of metastatic lesions. Further investigation is warranted to elucidate the true nature of the association between platinum sensitivity, CD133 expression, and the risk and prognosis of CNS metastases from EOC.

Keywords: Brain metastases, Chemoresistance, Prognosis, Stem cell marker

\footnotetext{
*Correspondence: abaskys@ucr.edu; neurosurg@126.com

${ }^{\dagger}$ Equal contributors

${ }^{3}$ Riverside Psychiatric Medical Group and School of Medicine, University of California Riverside, 5887 Brockton Avenue, Ste. B, Riverside, CA 92506, USA

${ }^{2}$ Department of Obstetrics and Gynecology, Xijing Hospital, Fourth Military

Medical University, West Changle Road, No.127, Xi'an 710032 Shaanxi

Province, People's Republic of China

Full list of author information is available at the end of the article
} 


\section{Background}

The estimated incidence of central nervous system (CNS) metastases in patients with epithelial ovarian cancer (EOC) is $1.01 \%$ (range from $0.49 \%-2.2 \%$ ) [1]. Recently, an increased incidence of CNS metastases in EOC has been reported [2-4], possibly due to a result of better control of the primary cancer, advances in CNS imaging techniques, and use of platinum-based chemotherapies [4]. Platinum compounds do not pass the blood-brain barrier (BBB), leaving the CNS more vulnerable to the growth of cancer cells [4], and reportedly platinum could damage the $\mathrm{BBB}$ facilitating metastatic cancer cell entry [5]. Increasing prevalence of CNS metastases associated with EOC underscores the importance of and the need for a better understanding of this clinical entity. However, in most centers, diagnostic brain imaging is not a routine procedure during the follow-up workup for EOC, and the standard monitor tools such as CA-125 do not reliably predict CNS metastases.

It has been shown that prognostic factors for EOC patients with CNS metastases vary. Thus, a high performance status [6,7], absence of extracranial lesions accompanying CNS metastases $[8,9]$, single metastases $[7,8]$, platinum sensitivity [7], a longer time to develop CNS metastases [10], recursive partitioning analysis class [11], and a multimodal therapy for CNS lesions $[9,11,12]$ are often associated with a more favorable prognosis. CD133 (prominin-1), a 5-transmembrane glycoprotein [13] that is a putative marker for cancer stem cells (CSCs) in solid tumors including ovarian cancer, has been thought to define a subpopulation of tumor-initiating cells with enhanced resistance to platinum [14-16]. CD133 expression was shown to be an unfavorable prognostic factor for overall and disease-free survival in patients with ovarian cancer, which is also associated with poor response to platinumbased chemotherapy [17]. However, CD133 expression has not been evaluated in patients with CNS metastases. In addition, as a marker for "stemness", CD133 is shown to be associated with brain tumor stem cells that play key roles in both brain tumor initiation and recurrence because of their capacity for self-renewal and inherent chemo- and radio-resistance [18]; but limited data are available on its role in tumor metastasis.

In this study we examined possible predictors of CNS metastases associated with EOC, and attempted to define a subgroup of vulnerable patients for whom special attention should be paid when monitoring and managing disease progression and CNS metastases.

\section{Methods}

\section{Patients}

Patient records at Xijing Hospital (Xi'an, People's Republic of China) between January 2002 and December 2011 were included in the study if they had pathologically confirmed
EOC. Patients excluded from the study were those with 1) a past history of malignancy other than EOC, 2) a synchronous primary tumor of other organs and 3) a nonepithelial histologic type of ovarian cancer. Demographic, clinical, and pathologic data related to the primary cancer were obtained from the institution's medical records database. Patients were divided into platinum sensitive (complete clinical remission with a treatment-free interval $>6$ months after prior platinum therapy) or platinum resistant (progression or relapse within 6 months) groups [7,17]. Among all the 1366 patients with EOC, 29 with CNS malignancies were identified. The patients' demographic and clinical characteristics were reevaluated regarding the presence of CNS metastases. During the study period, there was no established treatment protocol for these patients with CNS metastases whose treatments were retrospectively reviewed. Thirty-one pathology-matched EOC patients with at least 1 relapse of disease but without CNS metastases were used as the control. Approval was obtained from the Institutional Review Board of Xijing Hospital, Fourth Military Medical University to perform this study and to use archived material for research purposes.

\section{Immunohistochemistry}

Immunohistochemistry was done as previously described [17]. Briefly, rabbit polyclonal antibody against CD133 (Abcam, Cambridge, UK) was used to detect CD133 expression in the EOC tissues of all patients with $(N=29)$ and without $(N=31)$ CNS metastases and the metastatic CNS tumor tissues obtained during neurosurgery $(N=19)$, using the standard two-step indirect immunohistochemical staining method. We used the glioblastoma tissue as a positive control of CD133 (Figure 1F). Omitting CD133 antibody during the primary antibody incubation served as a negative control (Figure 1E).

Assessment of CD133 expression was done independently by two observers (BLL and HC) blinded to clinicopathological information. Presence of either membrane and/or cytoplasmic staining were considered a positive signal, and the score of each sample was calculated as a mean proportion of positive cells (range, 0-100\%) in two continuous sections. For statistical analysis, all cases were divided into CD133- (0\% CD133+ tumor cells) and CD133+ (>0\% CD133+ tumor cells, i.e. containing at least one CD133+ cell) $[17,19]$.

\section{Statistical analysis}

The time to diagnosis of CNS metastases was calculated from the time of primary cancer surgery to the time of imaging diagnosis of CNS lesions. Overall survival (OS) after the diagnosis of CNS metastases was calculated from the time of imaging diagnosis to the time of death as a result of any cause. Patients who were alive at the time of the last 


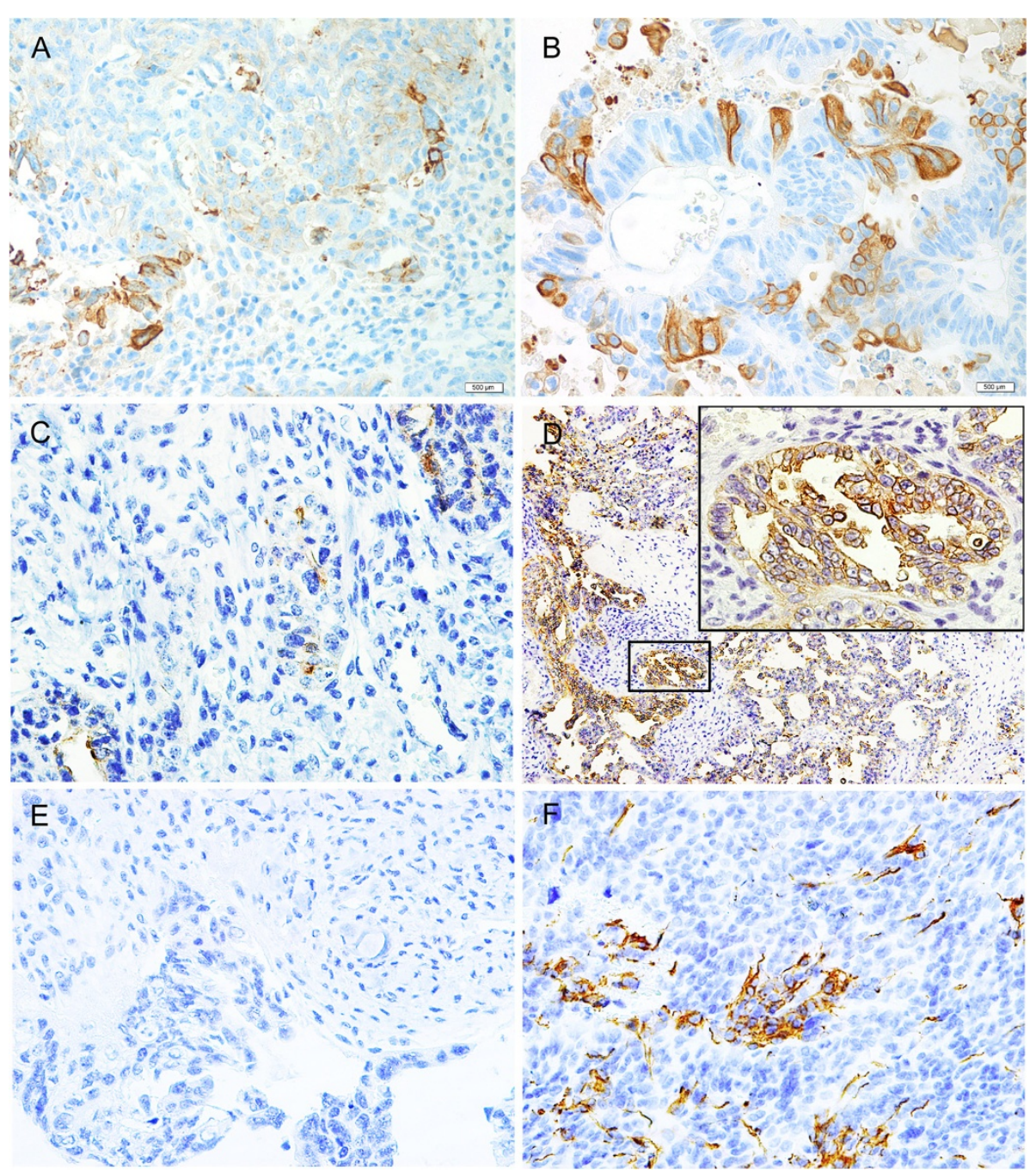

Figure 1 Representative example of CD133 immunoreactivity pattern in ovarian cancer and CNS metastases (original magnification, x40). (A) Cell membrane expression in ovarian serous cystadenocarcinoma. (B) Cell membrane and cytoplasmic expression in ovarian mucinous cystadenocarcinoma. (C) Positive single cell expression pattern in CNS metastases from ovarian cancer. (D) Positive cluster formation in CNS metastases from ovarian cancer (original magnification, x10, insert showing higher magnification, $\times 40$ ). (E) Negative control. (F) Positive control of glioblastoma.

follow-up (November of 2012) were censored. Probability of survival was estimated using the Kaplan-Meier method. Differences in survival were tested by the log-rank test for univariate comparisons. A multivariate analysis with Cox proportional hazards model was done to establish independent predictor(s) for time to CNS metastases and OS after CNS metastases, whereas a multivariate analysis with binary and multinomial logistic regression was done to establish risk factors for the development of CNS metastases. To test whether frequency distributions differed across categorical variables, the Fisher exact test was used. Statistical significance was set at $P<0.05$, based on $N=29$ cases, unless indicated otherwise. Statistical analysis was performed using SPSS software (version 16.0, SPSS, Inc., Chicago, IL, USA).

\section{Results}

\section{Patient characteristics}

Of 1366 patients diagnosed with EOC, 29 (2.1\%) developed CNS metastases. The major clinical characteristics of these 29 patients at the time of diagnosis of primary cancer are summarized in Table 1 . The median age was 57 years (range from 37 to 74 years). All patients but 1 had received initial platinum-based chemotherapy. Demographic and clinical features were not significantly different between the EOC patients with CNS metastases and control group (Table 2).

Diagnosis of CNS metastases was based on CNS imaging abnormalities in all patients and was pathologically confirmed after neurosurgery in 19 patients. The patient characteristics at the time of diagnosis of CNS metastases 
Table 1 Major clinical characteristics related to primary EOC and its association with CD133 expression

\begin{tabular}{ccccc}
\hline Parameter & \multicolumn{3}{c}{ No. of patients (\%) } & P value \\
\cline { 2 - 3 } & $\begin{array}{c}\text { CD133-negative } \\
\text { expression }\end{array}$ & $\begin{array}{c}\text { CD133-positive } \\
\text { expression }\end{array}$ & Total & \\
\hline Age (yrs) & $10(62.5)$ & $6(37.5)$ & 16 & 0.272 \\
$<60$ & $5(38.5)$ & $8(61.5)$ & 13 & \\
$>=60$ & & & & 1.000 \\
FIGO stage & $2(66.7)$ & $1(33.3)$ & 3 & \\
1,2 & $13(50.0)$ & $13(50.0)$ & 26 & \\
3,4 & & & & $0837+$
\end{tabular}

Pathology of primary cancer

$\begin{array}{lccl}\text { Serous } & 8(50.0) & 8(50.0) & 16 \\ \text { Mucinous } & 2(100) & 0(0) & 2 \\ \begin{array}{l}\text { Endometrioid } \\ \text { Clear cell }\end{array} & 1(50.0) & 1(50.0) & 2 \\ \begin{array}{l}\text { Mixed } \\ \text { epithelial }\end{array} & 1(100) & 0(0) \\ \begin{array}{l}\text { Undifferentiated } \\ \text { Histological grade* }\end{array} & 1(66.7) & 3(60.0) & 5 \\ 1,2 & 3(60.0) & 2(40.0) \\ 3, & 8(44.4) & 10(55.6) & 18\end{array}$

Extent of surgical resection

$\begin{array}{lccc}\text { TAH + BSO } & 13(56.5) & 10(43.5) & 23 \\ \text { Limited } & 2(40.0) & 3(60.0) & 5 \\ \text { Biopsy } & 0(0) & 1(100) & 1\end{array}$

Lymph node metastasis

Yes $\quad 9(50.0)$

Ascites at the time of primary surgery

$\begin{array}{llll}\text { Yes } & 10(52.6) & 9(47.4) & 19 \\ \text { No } & 5(50.0) & 5(50.0) & 10\end{array}$

Adjuvant therapy

\begin{tabular}{lcccc} 
Chemotherapy & $14(56.0)$ & $11(44.0)$ & 25 & \\
$\begin{array}{l}\text { Chemotherapy } \\
\text { + Radiotherapy }\end{array}$ & $1(66.7)$ & $2(33.3)$ & 3 & \\
None & $0(0)$ & $1(100)$ & 1 & \\
$\begin{array}{l}\text { Platinum sensitivity } \\
\text { Sensitive }\end{array}$ & $12(75.0)$ & $4(25.0)$ & 16 & \\
Resistant & $2(16.7)$ & $10(83.3)$ & 12 & \\
\hline
\end{tabular}

Abbreviations: TAH Total abdominal hysterectomy, BSO Bilateral salpingooophorectomy.

*Where data were available.

$+P$ value was caculated by comparing serous vs. non-serous groups.

are presented in Table 3. The median age at diagnosis of CNS metastases was 59 years (range from 39 to 76 years). Neurological deficits (including motor, sensory or cranial nerve damage), headache (with/without
Table 2 Major clinical characteristics and CD133 expression of EOC patients with vs. without CNS metastases

\begin{tabular}{|c|c|c|c|}
\hline \multirow[t]{2}{*}{ Parameter } & \multicolumn{2}{|c|}{ No. of patients (\%) } & \multirow[t]{2}{*}{$P$ value } \\
\hline & $\begin{array}{l}\text { EOC w/ CNS } \\
\text { metastases }\end{array}$ & $\begin{array}{c}\text { EOC w/o CNS } \\
\text { metastases }\end{array}$ & \\
\hline Age (yrs) & & & 0.599 \\
\hline$<60$ & $16(55.2)$ & $15(48.4)$ & \\
\hline$>=60$ & $13(44.8)$ & $16(51.6)$ & \\
\hline FIGO stage & & & 0.666 \\
\hline 1,2 & $3(10.3)$ & $2(6.5)$ & \\
\hline 3,4 & $26(89.7)$ & $29(93.5)$ & \\
\hline Pathology of primary cancer & & & $0.979+$ \\
\hline Serous & $16(55.2)$ & $17(54.8)$ & \\
\hline Mucinous & $2(6.9)$ & $2(6.5)$ & \\
\hline Endometrioid & $2(6.9)$ & $2(6.5)$ & \\
\hline Clear cell & $1(3.4)$ & $2(6.5)$ & \\
\hline Mixed epithelial & $5(17.2)$ & $5(16.1)$ & \\
\hline Undifferentiated & $3(10.3)$ & $3(9.7)$ & \\
\hline Histological grade* & & & 0.724 \\
\hline 1,2 & $5(21.7)$ & $4(16.7)$ & \\
\hline 3 & $18(78.3)$ & $20(83.3)$ & \\
\hline Extent of surgical resection & & & 0.572 \\
\hline $\mathrm{TAH}+\mathrm{BSO}$ & $23(79.3)$ & $26(83.9)$ & \\
\hline Limited & $5(17.2)$ & $5(16.1)$ & \\
\hline Biopsy & $1(3.4)$ & $0(0)$ & \\
\hline Lymph node metastasis & & & 0.313 \\
\hline Yes & $18(62.1)$ & $23(74.2)$ & \\
\hline No & $11(37.9)$ & $8(25.8)$ & \\
\hline Ascites at the time of primary & irgery & & 0.650 \\
\hline Yes & $19(46.3)$ & $22(52.6)$ & \\
\hline No & $10(53.7)$ & $9(47.4)$ & \\
\hline Adjuvant therapy & & & 0.674 \\
\hline Chemotherapy & $25(86.2)$ & $24(77.4)$ & \\
\hline $\begin{array}{l}\text { Chemotherapy + } \\
\text { Radiotherapy }\end{array}$ & $3(10.3)$ & $5(16.1)$ & \\
\hline None & $1(3.4)$ & $2(6.5)$ & \\
\hline Platinum sensitivity & & & 0.516 \\
\hline Sensitive & $16(57.1)$ & $19(65.5)$ & \\
\hline Resistant & $12(42.9)$ & $10(34.5)$ & \\
\hline CD133 expression & & & 0.018 \\
\hline Negative & $15(51.7)$ & 25 (80.6) & \\
\hline Positive & $14(48.3)$ & $6(19.4)$ & \\
\hline
\end{tabular}

Abbreviations: TAH Total abdominal hysterectomy, BSO Bilateral salpingooophorectomy.

* Where data were available.

$+P$ value was caculated by comparing serous vs. non-serous groups. 
Table 3 Major clinical characteristics related to CNS metastases and its association with CD133 expression

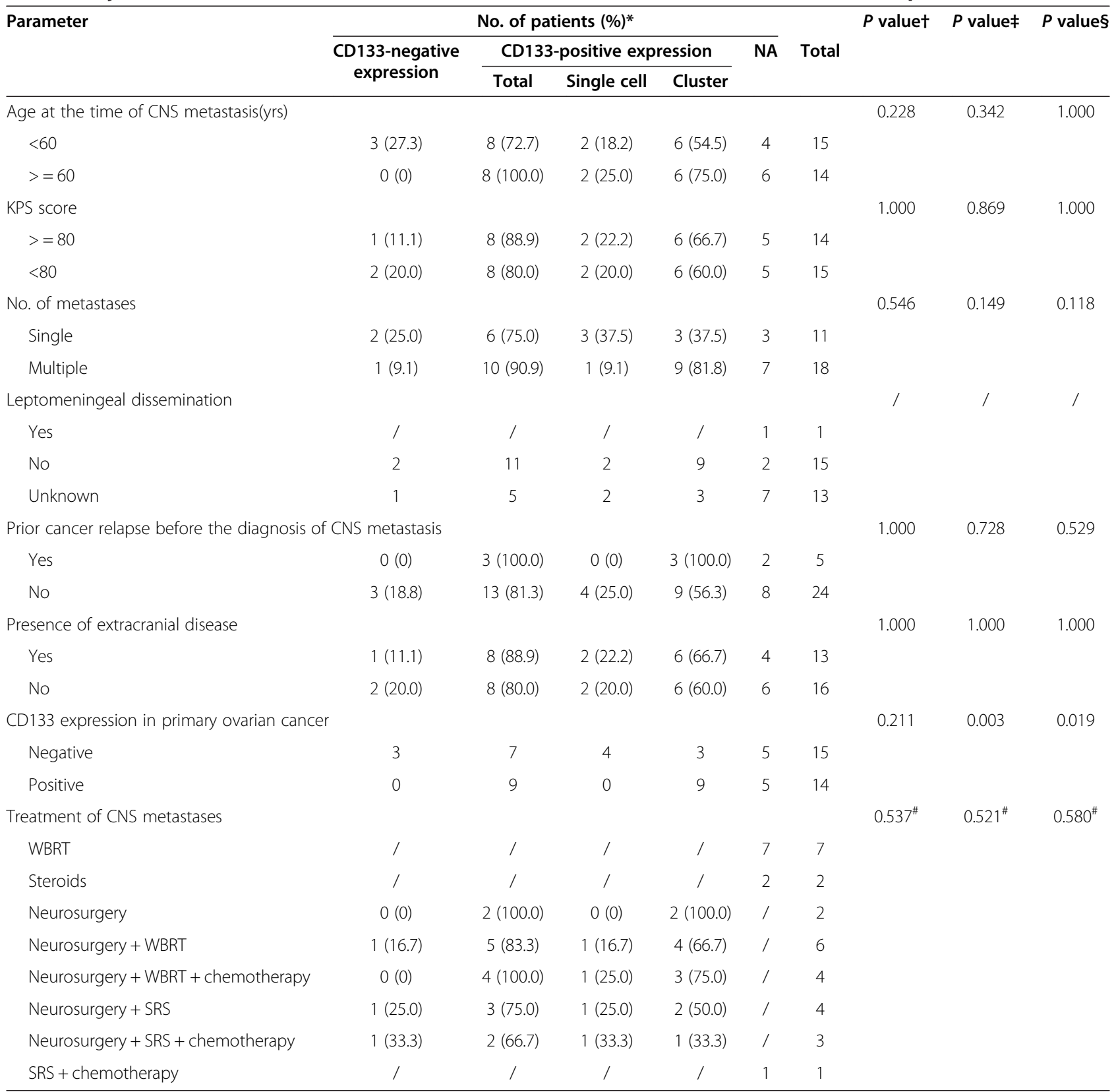

Abbreviations: NA Not available, KPS Karnofsky performance status, WBRT Whole-brain radiation therapy, SRS Stereotactic radiosurgery.

*Percentage (\%) represented the proportion of each group in 19 patients whose tumor tissues were available.

$\dagger P$ values were calculated by comparing CD133-negative vs. CD133-positive groups in 19 patients whose tumor tissues were available.

$\ddagger P$ values were calculated by comparing CD133-negative vs. CD133-positive single cell vs. CD133-positive cluster groups in 19 patients whose tumor tissues were available.

$\S P$ values were calculated by comparing CD133-positive single cell vs. CD133-positive cluster groups in 16 patients whose tumor tissues were stained CD133 positive.

${ }^{\#} P$ values were calculated by comparing neurosurgery + WBRT +/- chemotherapy vs. neurosurgery + SRS +/- chemotherapy groups.

nausea and vomiting) and seizures were the most common neurological symptoms and occurred in 17 patients (58.6\%), 12 patients $(41.3 \%)$, and 5 patients $(17.2 \%)$, respectively. Less common symptoms included altered mental status, dizziness and speech difficulties. In this cohort, 1 patient (3.4\%) had leptomeningeal dissemination, 5 patients (17.2\%) had intraperitoneal relapse before the disease metastasized to CNS, and 13 patients (44.8\%) developed concurrent metastases to other organs at the time of the diagnosis of intracranial lesions.

Among the 29 patients, a multimodal approach (combination of at least two treatment modalities including neurosurgery, whole-brain radiation therapy [WBRT], stereotactic radiosurgery [SRS] and chemotherapy) was the 
main treatment, accounting for $62.1 \%$ (18 patients). The remaining patients received a monotherapy of either WBRT, neurosurgery, or steroids (7, 2, and 2 patients respectively). Of the 19 neurosurgeries performed either alone or in combination with other modalities, 9 (47.4\%) cases were solitary CNS metastases and 10 (52.6\%) cases represented multiple lesions.

\section{Immunohistochemical study of CD133 in primary EOC and CNS metastases}

Expression of CD133 in primary and metastatic tumor tissues was present in the membrane and/or cytoplasm, sometimes with a low level of heterogeneity (Figure 1A-D). CD133+ staining was observed in 14 out of 29 (48.3\%) primary EOC samples with CNS metastases, 6 out of 31 (19.4\%) EOC samples without CNS metastases and 16 out of 19 (84.2\%) CNS metastatic tissue samples. The number of CD133+ tumor cells ranged from $0 \%$ to 39\% (mean 6\%) in primary EOC with CNS metastases, from $0 \%$ to $33 \%$ (mean 2\%) in EOC without CNS metastases, and from $0 \%$ to $42 \%$ (mean $10 \%$ ) in the 19 CNS metastatic tissue samples. The distribution of CD133 expression in primary EOC with CNS metastases is summarized in Table 1 according to the clinicopathologic characteristics. Absence of CD133 expression in primary EOC with CNS metastases was associated with a higher platinum sensitivity. Specifically, CD133+ expression was observed in $25.0 \%$ (4 of 16) patients with platinum-sensitive disease $v s .83 .3 \%$ (10 of 12$)$ in platinum-resistant disease $(P=0.006)$. Similar finding was observed in recurrent EOC without CNS metastases, with CD133+ expression being detected in $5.2 \%$ (1 of 19 ) platinum-sensitive patients $v s .40 .0 \%$ (4 of 10) platinum-resistant patients $(P=0.036)$. No other association was found between CD133+ expression and the clinicopathologic parameters in either EOC with CNS metastases or control group (data not shown).

Results of CD133 expression analysis in CNS metastatic tissue are shown in Table 3. The expression level was high in CNS metastases, suggesting that the categorization of patients in CD133+ vs. CD133- may have been biased considering the possible quantitative effect of CD133+ cells [20]. To reduce the bias, we divided samples into a single cell (Figure 1C) and cluster-type staining based on their topology. A cluster was defined as an aggregation of more than five CD133+ cells [21] and sections with at least one cluster were classified as "cluster + type". CD133+ cell clusters (Figure 1D) more frequently occurred in CNS metastases $(63.2 \%, 12$ of 19 patients) but were relatively uncommon in primary EOC (24.1\%, 7 of 29 patients). This difference was significant $(P=0.015)$. However, CD133+ cell cluster formation in CNS metastases was associated with $\mathrm{CD} 133+$ expression in primary EOC $(P=0.003)$ (Table 3). There was no correlation between the percentage of CD133+ cells in the metastases and the corresponding primary EOC; but there was a correlation between the CD133+ category (samples with >0\% CD133+ cells) in the metastases and primary EOC (Spearman's rank correlation coefficient, $\mathrm{r}=0.706 ; P=0.001)$. CD133 expression status was concordant between primary and CNS metastatic sites in 12 patients (63.2\%) and no statistically significant difference was observed (kappa $=0.289$, $P=0.211$, Table 4). Of the 7 discordant cases, all had CD133+ expression in CNS metastases but not in primary tumors. We analyzed the difference between the concordant and discordant cases according to clinicopathologic parameters at the time of initial EOC diagnosis and found no differences (data not shown). There was no other association observed between CD133+ expression (or cluster formation) and the clinicopathologic parameters examined (Table 3).

\section{Risk factors associated with the development of CNS metastases}

As shown in Table 2, CD133+ expression was the only factor associated with an increased risk of CNS metastases in recurrent EOC patients, which was significantly different between EOC patients with and without CNS metastases $(P=0.018)$.

Results of binary logistic regression showed that lymph node metastasis at initial surgery and CD133 expression were significantly associated with an increased risk of CNS metastases (data not shown).

Multivariate logistic regression demonstrated CD133 expression in primary tumor as the only independent risk factor for CNS metastases (HR, 4.72; 95\% CI, 1.10-20.41; $P=0.037$ ) (Table 5).

Risk factors associated with shorter times to the diagnosis of CNS metastases

Among the 29 patients with CNS metastasis, the median time to the diagnosis of CNS metastases was 23.5 months (range from 6.2-75.0 months).

A univariate analysis of risk factors associated with a shorter time to CNS metastases is shown in Table 6. Factors including International Federation of Gynecology and Obstetrics (FIGO) stage, extent of surgical resection, lymph node metastasis at initial surgery, platinum sensitivity, and CD133 expression were significantly related to the time of the CNS metastases diagnosis.

\section{Table 4 CD133 expression in primary EOC and corresponding CNS metastatic sites}

\begin{tabular}{lcc}
\hline CD133 expression status & No. of CD133- (P) & No. of CD133+ (P) \\
\hline No. of CD133- (M) & 3 & 0 \\
No. of CD133+ (M) & $7^{*}$ & 9 \\
\hline
\end{tabular}

Abbreviations: $P$ Primary tumors, $M$ Corresponding CNS metastatic sites. $P$ value $=0.211$

*Discordant cases. 
Table 5 Multivariate logistic regression for risk of CNS metastases

\begin{tabular}{lcc}
\hline Variable & HR $(\mathbf{9 5} \% \mathbf{C l})$ & $\boldsymbol{P}$ value \\
\hline Age $>=60$ yrs & $2.74(0.60-12.58)$ & 0.195 \\
FIGO stage: 3,4 vs. 1,2 & $2.79(0.42-18.52)$ & 0.289 \\
Pathology: serous vs. non-serous & $1.87(0.42-8.23)$ & 0.409 \\
Surgical resection: TAH + BSO vs. & $1.39(0.26-7.59)$ & 0.703 \\
Limited and Biopsy & & \\
Presence of lymph node metastasis & $4.17(0.94-16.67)$ & 0.053 \\
Presence of ascites & $1.84(0.23-14.71)$ & 0.566 \\
Platinum resistance & $4.15(0.83-20.83)$ & 0.083 \\
CD133 expression & $4.72(1.10-20.41)$ & 0.037 \\
\hline
\end{tabular}

Abbreviations: TAH Total abdominal hysterectomy, BSO Bilateral salpingooophorectomy.

Multivariate analysis showed that a smaller extent of surgical resection (HR, 5.91; 95\% CI, 1.02-34.24; $P=0.047$ ) and platinum resistance $(\mathrm{HR}, 5.41 ; 95 \% \mathrm{CI}, 1.63-17.99$; $P=0.006)$ were independent predictors for a shorter time to the diagnosis of CNS metastases (Table 7, Figure 2).

\section{Prognostic factors associated with OS after the diagnosis of CNS metastases}

The median OS since the primary EOC was 3.35 years (95\% CI, 2.75-3.95 years), with 1-, 3-, and 5-year survival probabilities being $96.6 \%, 62.1 \%$, and $17.2 \%$, respectively. The median OS since CNS metastases was 13.2 months (95\% CI, 6.9-19.5 months), with 6-month, 1-year, and 3 -year survival probabilities being $82.8 \%, 55.2 \%$, and $9.2 \%$, respectively. Twenty-seven of $29(93.1 \%)$ patients died within the follow-up period. Of the 19 patients whose treatment included neurosurgery, the median OS since the diagnosis of CNS metastases was 17.0 months (95\% CI, 11.6-22.4 months), which was significantly longer than that of the 10 patients treated without neurosurgery (8.0 months, $95 \% \mathrm{CI}, 4.5-16.2$ months, $P=0.004$ ).

Univariate analysis showed significant association between OS and the following parameters: platinum sensitivity, CD133 expression in primary EOC, number of CNS metastases, treatment strategies for CNS metastases, and CD133 expression in CNS metastases (Table 8). Shorter time to CNS metastases diagnosis was not associated with decreased survival.

Multivariate Cox proportional hazards model including variables with $P<0.05$ in the univariate analysis were analyzed to evaluate independent predictors of OS. Platinum resistance (HR, 5.13; 95\% CI, 1.28-20.57; $P=0.021)$, multimodal therapy incorporating SRS for CNS metastases (HR, 0.12; 95\% CI, 0.03-0.55; $P=0.007$ ), and CD133 cluster formation in CNS metastases (HR, 12.08; 95\% CI, $1.55-94.16 ; P=0.017$ ) were found to influence OS significantly and independently (Table 9, Figure 3 ).
Table 6 Univariate analysis for predictors of time to CNS metastases

\begin{tabular}{|c|c|c|c|}
\hline Variables & $\begin{array}{c}\text { No. of } \\
\text { patients (\%) }\end{array}$ & $\begin{array}{c}\text { Median time to } \\
\text { CNS metastases, } \\
\text { mo }(95 \% \mathrm{Cl})\end{array}$ & $P$ value \\
\hline Age (yrs) & & & 0.056 \\
\hline$<60$ & $16(55.2)$ & $27.3(17.5-37.1)$ & \\
\hline$>=60$ & $13(44.8)$ & $22.9(14.4-29.4)$ & \\
\hline FIGO stage & & & 0.021 \\
\hline 1,2 & $3(10.3)$ & $45.1(10.5-79.7)$ & \\
\hline 3,4 & $26(89.7)$ & $22.7(18.7-26.7)$ & \\
\hline Pathology of primary cancer & & & 0.595 \\
\hline Serous & $16(55.2)$ & $25.7(16.5-34.9)$ & \\
\hline Non-serous & $13(44.8)$ & $22.7(20.8-24.6)$ & \\
\hline Histological grade & & & 0.354 \\
\hline 1,2 & $5(21.7)$ & $27.7(18.7-36.7)$ & \\
\hline 3 & $18(78.3)$ & $21.9(17.1-26.7)$ & \\
\hline Extent of surgical resection & & & $<0.0001^{*}$ \\
\hline $\mathrm{TAH}+\mathrm{BSO}$ & $23(79.3)$ & $27.7(23.0-32.4)$ & \\
\hline Limited & $5(17.2)$ & $16.3(15.4-17.2)$ & \\
\hline Biopsy & $1(3.4)$ & 6.2 & \\
\hline Lymph node metastasis & & & 0.026 \\
\hline No & $11(37.9)$ & $31.7(24.4-39.0)$ & \\
\hline Yes & $18(62.1)$ & $22.0(21.6-22.4)$ & \\
\hline Ascites at the time of prima & ary surgery & & 0.153 \\
\hline No & $10(34.5)$ & $29.0(22.8-35.2)$ & \\
\hline Yes & $19(65.5)$ & $22.1(21.2-23.0)$ & \\
\hline Adjuvant therapy & & & $0.683 \dagger$ \\
\hline Chemotherapy & $25(86.2)$ & $25.3(20.4-30.2)$ & \\
\hline $\begin{array}{l}\text { Chemotherapy + } \\
\text { Radiotherapy }\end{array}$ & $3(10.3)$ & $21.9(14.9-28.9)$ & \\
\hline None & $1(3.4)$ & 23.5 & \\
\hline Platinum sensitivity & & & $<0.0001$ \\
\hline Sensitive & $16(57.1)$ & $29.0(16.8-41.2)$ & \\
\hline Resistant & $12(42.9)$ & $16.3(13.6-19.0)$ & \\
\hline CD133 expression & & & 0.033 \\
\hline Negative & $15(51.7)$ & $29.0(20.9-37.1)$ & \\
\hline Positive & $14(48.3)$ & $19.8(11.7-27.9)$ & \\
\hline
\end{tabular}

Abbreviations: TAH Total abdominal hysterectomy, BSO Bilateral salpingooophorectomy.

${ }^{*} P<0.0001$ for TAH + BSO vs. Limited and for TAH + BSO vs. Biopsy, $P=0.025$ for Limited vs. Biopsy.

$\dagger P=0.683$ for Chemotherapy vs. None, $P=0.956$ for Chemotherapy vs. Chemotherapy + Radiotherapy, $P=0.918$ for Chemotherapy + Radiotherapy vs. None.

\section{Discussion}

CNS metastases represent a late manifestation of EOC and are associated with extremely poor prognosis regardless of the treatment $[1,4]$. One of the main findings of this study is that the extent of surgical resection and 
Table 7 Multivariate Cox proportional hazards regression for time to CNS metastases

\begin{tabular}{lcc}
\hline Variable & HR $(\mathbf{9 5} \% \mathbf{C l})$ & $\boldsymbol{P}$ value \\
\hline Age $>=60$ yrs & $1.38(0.50-3.82)$ & 0.536 \\
FIGO stage: 3,4 vs. 1,2 & $3.65(0.38-35.21)$ & 0.263 \\
Surgical resection: TAH + BSO vs. & $5.91(1.02-34.24)$ & 0.047 \\
Limited and Biopsy & & \\
Presence of lymph node metastasis & $2.65(0.91-7.71)$ & 0.074 \\
Platinum resistance & $5.41(1.63-17.99)$ & 0.006 \\
CD133 expression & $1.24(0.46-3.34)$ & 0.665 \\
\hline
\end{tabular}

Abbreviations: TAH Total abdominal hysterectomy, BSO Bilateral salpingooophorectomy.

platinum sensitivity of primary EOC were the independent risk predictors for time to CNS metastases. This is in keeping with previous observations that the size of residual tumor after surgery is one of the most important prognostic factors for survival of advanced EOC [22,23]. Our results reemphasize that all attempts should be made to achieve complete cytoreduction or optimal $(<1 \mathrm{~cm})$ residual disease in order to prolong the survival of EOC patients and delay disease progression and metastasis.

Given that the current guidelines for the management of EOC should be individualized according to the patient status, gynecologists must balance the risk of rapid metastases against the costs and adverse effects that accompany aggressive interventions. It has been shown by Sehouli et al. [7] and confirmed by our study that platinum sensitivity is an independent prognostic factor for a favorable outcome in patients with CNS metastases from EOC. In addition, our results showed a detrimental impact of platinum resistance on the time to the development of CNS metastases. Taken together, these findings suggest that patients who are unable to achieve optimal cytoreduction and/or who present with platinum resistance might benefit from more aggressive treatment intended to better control the primary disease, and have a possible delay of CNS metastases. Physicians should also pay more attention to the presence of neurological symptoms in this group of patients and arrange CNS imaging for early diagnosis and prompt treatment of metastases. In addition, having a biomarker, which is associated with the metastatic disease would allow this population of patients to be screened appropriately. Our results indicate a positive association between CD133+ expression in primary tumor and increased risk of CNS metastases, and thus hold promise for further validation of the application of this molecule as a biomarker in disease monitoring and management.

Regarding the prognostic factors for CNS metastases from EOC, the findings that platinum sensitivity [7] and multimodal treatment $[9,12]$ have a positive impact on OS are supported by our results. Moreover, we for the first time compared the expression of CD133, a putative CSC marker, in both the primary EOC and its corresponding CNS metastases, and described its predictive role for CNS metastases.

The fraction of CD133+ cells are enriched in several kinds of solid tumors including the ovarian cancer, which are presented with enhanced resistance to platinum-based chemotherapy [14,24]. To this end, patients with CD133+ tumor cells are more likely to experience platinum resistance (also confirmed by our results) and thus a less than satisfactory outcome of the primary cancer management. In addition, CD133+ ovarian cancer cells display a potential of CSCs [14], which may be associated with more aggressive tumor growth and poor prognosis in ovarian cancer patients [17]. Several recent studies have also demonstrated CD133 as a metastasis-related molecule. Specifically CD133 + CXCR4+ cancer cells had a high metastatic capacity in liver metastases of colorectal tumors [25], metastatic pancreatic cancers [26], while overexpression of CD133, CD44v6 and human tissue factor was associated with pancreatic carcinoma metastasis [27]. In agreement with these, we found that $\mathrm{CD} 133+$ expression in
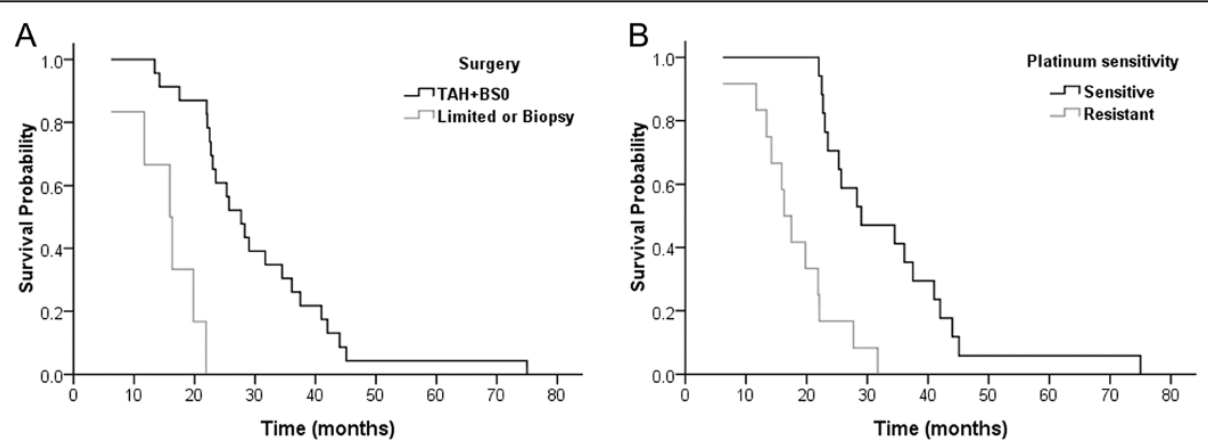

Figure 2 Kaplan-Meier curves of cumulative central nervous system (CNS)-metastases-free survival (time to CNS metastases) in 29 patients with CNS metastases from ovarian cancer. (A) Total abdominal hysterectomy + bilateral salpingo-oophorectomy (TAH + BSO) vs. limited surgery or biopsy. Result of multivariate Cox regression; HR, 5.91; $95 \% \mathrm{Cl}, 1.02-34.24 ; P=0.047$. (B) Platinum-resistant vs. platinum-sensitive disease. Result of multivariate Cox regression; HR, 5.41; 95\% Cl, 1.63-17.99; $\mathrm{P}=0.006$. 
Table 8 Univariate analysis for predictors of OS since CNS metastases

\begin{tabular}{lcc}
\hline Variables & $\begin{array}{c}\text { No. of } \\
\text { patients } \\
(\%)\end{array}$ & $\begin{array}{c}\text { OS since CNS } \\
\text { metastases, } \\
\text { mo }(95 \% \mathrm{Cl})\end{array}$
\end{tabular}

Age (yrs) mo $(95 \% \mathrm{Cl})$

$<60$
$>=60$

$\begin{array}{ll}16(55.2) & 15.3(3.7-26.9) \\ 13(44.8) & 9.4(4.9-13.9)\end{array}$

FIGO stage

$$
1,2
$$$$
3,4
$$

Pathology of primary cancer

$$
\text { Serous }
$$

Non-serous

Histological grade

$$
1,2
$$$$
3,
$$

Extent of surgical resection

$$
\mathrm{TAH}+\mathrm{BSO}
$$

Limited

Biopsy

Lymph node metastasis

No

Yes

Ascites at the time of primary surgery

No
Yes
Adjuvant therapy
Chemotherapy
Chemotherapy + Radiotherapy
None
Platinum sensitivity

$10(34.5) \quad 15.3(1.7-28.9)$

$19(65.5) \quad 12.5(9.9-15.1)$

$25(86.2) \quad 15.3(8.0-22.6)$

$3(10.3) \quad 7.0(1.5-12.4)$

$1(3.4) \quad 32.3$

Sensitive

$16(57.1)$

$15.3(0.5-30.1)$

Resistant

$12(42.9)$

$9.4(0.1-18.9)$

CD133 expression in primary cancer

Negative

$15(51.7) \quad 25.5(10.4-40.6)$

VPositive

$14(48.3)$

$9.4(2.4-16.4)$

KPS score

$$
>=80
$$

$13.2(1.0-29.2)$

$<80$

$15(51.7) \quad 12.5(1.1-23.9)$

No. of metastases

$$
\begin{aligned}
& \text { Single } \\
& \text { Multiple }
\end{aligned}
$$$$
11(37.9)
$$$$
25.5(12.6-38.4)
$$

$18(62.1)$

$9.4(4.4-14.4)$

0.372

0.421

0.033
Table 8 Univariate analysis for predictors of OS since CNS metastases (Continued)

Prior cancer relapse before the diagnosis of CNS metastasis 0.053

$\begin{array}{lcc}\text { No } & 24(82.8) & 15.3(6.4-24.2) \\ \text { Yes } & 5(17.2) & 9.4(3.3-21.2)\end{array}$

Presence of extracranial disease

0.458

$\begin{array}{lll}\text { No } & 16(55.2) & 13.2(3.1-23.3)\end{array}$

$\begin{array}{lll}\text { Yes } & 13(44.8) & 12.5(5.4-19.6)\end{array}$

Treatment of CNS metastases

Steroids $2(6.9) \quad 1.0(0-5.292)$

Unimodal (WBRT or $\quad 9(31.0) \quad 8.0(3.0-13.0)$

Neurosurgery)

Multimodal including WBRT 10 (34.5) $\quad 13.2(7.5-18.9)$

(Neurosurgery + WBRT +/-

chemotherapy)

Multimodal including SRS

(SRS +/- neurosurgery +/-

chemotherapy)

$0.211^{*} \quad$ CD133 expression in CNS metastases

Negative

$3(15.8) \quad 42.1(31.4-46.2)$

Positive single cell

4 (21.1) $27.3(25.1-29.6)$

Positive cluster

$12(63.2) \quad 11.6(8.5-14.7)$

Time to CNS metastases (mo)

$$
<23.5
$$

$14(48.3) \quad 7.6(0.78-20.25)$

$>=23.5$

$15(51.7) \quad 15.3(1.41-29.19)$

Abbreviations: TAH Total abdominal hysterectomy, BSO Bilateral salpingooophorectomy, KPS Karnofsky performance status, WBRT Whole-brain radiation therapy, SRS Stereotactic radiosurgery.

${ }^{*} P=0.211$ for TAH + BSO vs. Limited, $P<0.0001$ for TAH + BSO vs. Biopsy, $P=0.025$ for Limited vs. Biopsy.

$+P=0.071$ for Chemotherapy vs. Chemotherapy + Radiotherapy, $P=0.412$ for $0.071+\quad$ Chemotherapy vs. None, $P=0.182$ for Chemotherapy + Radiotherapy vs. None. $\ddagger P=0.027$ for Steroids vs. Unimodal, $P<0.0001$ for Steroids vs. Multimodal including WBRT, $P=0.001$ for Steroids $v$ s. Multimodal including SRS, $P=0.022$ for Unimodal vs. Multimodal including WBRT, $P<0.0001$ for Unimodal vs. Multimodal including SRS, $P=0.020$ for Multimodal including WBRT vs. Multimodal including SRS.

$\S P=0.005$ for negative vs. positive cluster,$P=0.023$ for positive single cell $v s$. positive cluster, $P=0.075$ for negative vs. positive single cell.

primary EOC was the only independent risk factor for CNS metastases. The fact that all other clinicopathologic parameters were not risk factors indicated that without assessment of the molecular behavior of the primary disease, it may be hard to identify recurrent EOC patients with high risk of CNS metastases who need close observation.

Our data do not support the role of CD133 expression in primary EOC as a significant predictor of the time to CNS metastases diagnosis or subsequent survival of patients with CNS metastases. This is despite CD133 association with platinum sensitivity, a predictor for both CNS-metastases-free survival and OS and could be attributed to a possible bias due to a small number of patients. Furthermore, CD133 may influence patient survival independently of its association with platinum sensitivity, as was shown in a colon cancer study, which found a 
Table 9 Multivariate Cox proportional hazards regression for OS after CNS metastases

\begin{tabular}{lcc}
\hline Variable & HR (95\% Cl) & $\boldsymbol{P}$ value \\
\hline Platinum resistance & $5.13(1.28-20.57)$ & 0.021 \\
CD133 expression in primary ovarian cancer & $2.82(0.66-12.17)$ & 0.163 \\
Multiple CNS metastases & $1.11(0.20-6.12)$ & 0.921 \\
Multimodal therapy including SRS & $0.12(0.03-0.55)$ & 0.007 \\
(SRS +/- neurosurgery +/- chemotherapy) & & \\
for CNS metastases & & \\
CD133 cluster formation in CNS metastases & $12.08(1.55-94.16)$ & 0.017 \\
\hline
\end{tabular}

Abbreviations: TAH Total abdominal hysterectomy, BSO Bilateral salpingooophorectomy, KPS Karnofsky performance status, WBRT Whole-brain radiation therapy, SRS Stereotactic radiosurgery.

downregulated CD133 expression in tumor epithelial cells after metastatic transition [28]. A transformation of primary cancer with CD133+ cells into metastasis consists of CD133- cells was observed, indicating that CD133- cells are also potent in tumor initiation [28]. On the other hand, when comparing EOC patients with and without CNS metastases, the overall survival was significantly better in CD133- expressing cases. Thus CD133 may be considered a hallmark of malignancy of primary disease with respect to CNS metastasis. However, its biological function might not be the only rate-limiting step considering that multiple molecular events are known to regulate the process of tumor metastasis [29].

We were able to show that CD133 cluster formation in CNS metastases could serve as a prognostic factor for OS and that CD133 clusters were significantly associated with prior $\mathrm{CD} 133+$ expression in primary EOC. However, the CD133+ expression was greater in the metastatic tissue. It is not inconceivable that the microenvironment for CSCs represented by $\mathrm{CD} 133+$ staining may be completely different in the CNS compared to the ovary affecting the proliferative or self-renewal potential of CSCs. Also, it has been demonstrated that a significant number of genes are differentially expressed in metastatic disease compared to primary ovarian cancer [30]. To better understand the role of a "stemness" marker of CD133 in the progression and metastasis of primary tumor, further studies are warranted preferably by analyzing a panel of potential "stemness" markers such as CD44, ALDH, EpCAM as well as CD133 in the future [14,31].

In most cases with CNS metastases from EOC, multimodal treatment approaches have been proven to greatly increase the therapeutic potential and significantly prolong the OS compared to unimodal approaches $[3,6,8,9,12,32]$. Though the optimal combination of modalities remains a matter of investigation, studies with a large sample size as well as meta-analyses showed that a combination of WBRT and neurosurgery with or without chemotherapy was most commonly applied with promising results. SRS has come into focus for the treatment of CNS metastases in recent years, as it is a noninvasive modality that provides good local control [33,34]. In addition, SRS is capable of treating lesions inaccessible to neurosurgery with an equivalent efficiency, which accounts for $50 \%$ of single CNS metastases [1]. Previous study on monotherapy with SRS has shown a remarkable increase in survival compared to WBRT (29 vs. 6 months) [35]. In the current study, improved survival was observed in patients treated with multimodal approach including SRS, compared to steroids, WBRT or neurosurgery alone, and multimodal approach including WBRT (27.3 vs. 1.0 vs. 8.0 vs. 13.2 months, $P<0.05$ in all instances, Figure 3B). In agreement with Kim et al. [11], we also found that the treatment modality including SRS was also the most important independent prognostic factor for CNS metastases from EOC.

This study has several limitations. Although we found that CD133 expression was a risk factor for the development of CNS metastases and that non-optimal cytoreduction and platinum resistance were risk factors for shorter time to the diagnosis of CNS metastases,

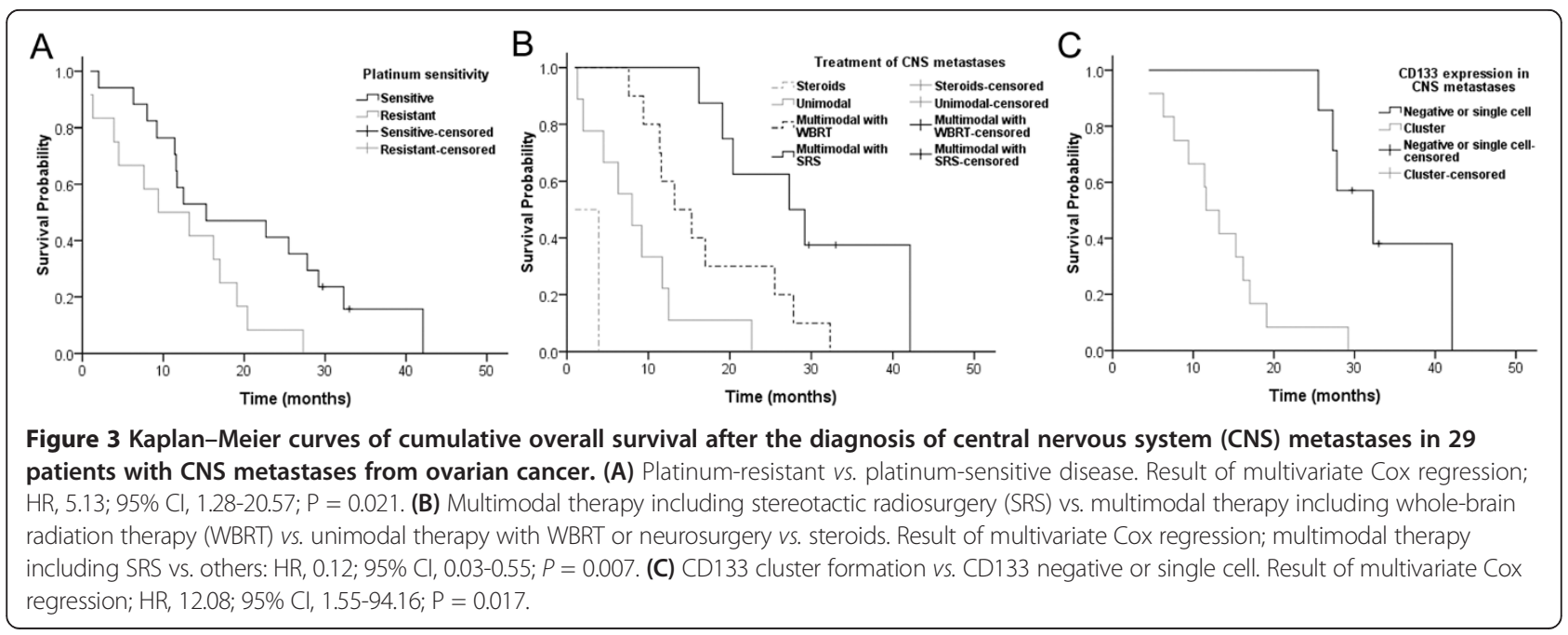


identification of other potential markers such as transcriptional factors [36-39] and immune factors [40-42] in primary EOC to indicate future cisplatin-refractory CNS-metastasis in EOC patients was outside the scope of this study. A genome-wide transcription analysis may identify other candidate molecules that have different expression levels in EOC patients with and without CNS metastases. Since this was a retrospective study, complete data were not available for all patients. Furthermore, our data represents the experience of a single institution and may not be fully generalizable. Since the number of patients with CNS metastases is small in any single institution, multicenter studies are needed to increase the statistical power. Finally, because CNS metastases in EOC patients often represent as a palliative situation, the quality-of-life should also be considered as an important endpoint.

\section{Conclusions}

In conclusion, our results show a significant association between positive expression of CD133 in primary EOC and an increased risk of CNS metastases. Higher platinum sensitivity is associated with a longer time to develop CNS metastases and a better prognosis of CNS metastases. Absence of CD133 clusters in metastatic tissue and use of multimodal treatment including SRS are associated with prolonged survival. Further investigation is warranted to elucidate the true nature of the association between platinum sensitivity, CD133 expression, and disease outcomes.

\section{Abbreviations \\ CNS: Central nervous system; EOC: Epithelial ovarian cancer; SRS: Stereotactic radiosurgery; BBB: Blood-brain barrier; CSCs: Cancer stem cells; OS: Overall survival; WBRT: Whole-brain radiation therapy; FIGO: International federation of gynecology and obstetrics; ALDH: Aldehyde dehydrogenase; \\ EpCAM: Epithelial cell adhesion molecule.}

\section{Competing interests}

The authors declare that they have no competing interests.

\section{Authors' contributions}

All the authors have made substantial contributions to conception and design, acquisition of data, or analysis and interpretation of data. BLL and SJL participated in the design of the study, carried out the

immunohistochemical studies, performed the statistical analysis, and were primarily responsible for drafting the manuscript. HC participated in the design of the study and the immunohistochemical studies, reviewed and confirmed the pathological diagnosis of tissue samples. YH and CX carried out collection of primary data and provided clinical input. HS and JL confirmed patients' outcomes and follow up results and help to coordinate the study. $A B$ and $X Y X$ conceived of the study, participated in its design and coordination, provided close guidance throughout the process, and helped to draft the manuscript. All authors read and approved the final manuscript.

\section{Acknowledgments}

We are grateful to Ms. Kathy Barton (University of California Riverside, School of Medicine) for her help in reviewing the manuscript and language editing.

\section{Author details}

${ }^{1}$ Department of Neurosurgery, Xijing Institute of Clinical Neuroscience, Xijing Hospital, Fourth Military Medical University, Xi'an, Shaanxi Province, People's
Republic of China. ${ }^{2}$ Department of Obstetrics and Gynecology, Xijing Hospital, Fourth Military Medical University, West Changle Road, No.127, Xi'an 710032 Shaanxi Province, People's Republic of China. ${ }^{3}$ Riverside Psychiatric Medical Group and School of Medicine, University of California Riverside, 5887 Brockton Avenue, Ste. B, Riverside, CA 92506, USA. ${ }^{4}$ Department of Pathology, Xijing Hospital, Fourth Military Medical University, Xi'an, Shaanxi Province, People's Republic of China. ${ }^{5}$ Department of Prosthodontics, School of Stomatology, Fourth Military Medical University, Xi'an, Shaanxi Province, People's Republic of China. ${ }^{6}$ Department of Dental Implantology, School of Stomatology, Fourth Military Medical University, Xi'an, Shaanxi Province, People's Republic of China.

Received: 9 April 2014 Accepted: 7 November 2014 Published: 17 November 2014

\section{References}

1. Pectasides $D$, Pectasides $M$, Economopoulos $T$ : Brain metastases from epithelial ovarian cancer: a review of the literature. Oncologist 2006, 11:252-260.

2. Bruzzone M, Campora E, Chiara S, Giudici S, Merlini L, Simoni C, Mammoliti S, Rubagotti A, Rosso R: Cerebral metastases secondary to ovarian cancer: still an unusual event. Gynecol Oncol 1993, 49:37-40.

3. Geisler JP, Geisler HE: Brain metastases in epithelial ovarian carcinoma. Gynecol Oncol 1995, 57:246-249.

4. Pietzner K, Oskay-Oezcelik G, El Khalfaoui K, Boehmer D, Lichtenegger W, Sehouli J: Brain metastases from epithelial ovarian cancer: overview and optimal management. Anticancer Res 2009, 29:2793-2798.

5. Namikawa K, Asakura M, Minami T, Okazaki Y, Kadota E, Hashimoto S: Toxicity of cisplatin to the central nervous system of male rabbits. Biol Trace Elem Res 2000, 74:223-235.

6. Melichar B, Urminska H, Kohlova T, Nova M, Cesak T: Brain metastases of epithelial ovarian carcinoma responding to cisplatin and gemcitabine combination chemotherapy: a case report and review of the literature. Gynecol Oncol 2004, 94:267-276.

7. Sehouli J, Pietzner K, Harter P, Munstedt K, Mahner S, Hasenburg A, Camara O, Wimberger P, Boehmer D, Buehling K, Richter R, El Khalfaoui K, Oskay-Ozcelik G: Prognostic role of platinum sensitivity in patients with brain metastases from ovarian cancer: results of a German multicenter study. Ann Oncol 2010, 21:2201-2205.

8. Anupol N, Ghamande S, Odunsi K, Driscoll D, Lele S: Evaluation of prognostic factors and treatment modalities in ovarian cancer patients with brain metastases. Gynecol Oncol 2002, 85:487-492.

9. Cohen ZR, Suki D, Weinberg JS, Marmor E, Lang FF, Gershenson DM, Sawaya R: Brain metastases in patients with ovarian carcinoma: prognostic factors and outcome. J Neurooncol 2004, 66:313-325.

10. Cormio G, Rossi C, Cazzolla A, Resta L, Loverro G, Greco P, Selvaggi L: Distant metastases in ovarian carcinoma. Int I Gynecol Cancer 2003, 13:125-129.

11. Kim TJ, Song S, Kim CK, Kim WY, Choi CH, Lee JH, Lee JW, Bae DS, Kim BG: Prognostic factors associated with brain metastases from epithelial ovarian carcinoma. Int J Gynecol Cancer 2007, 17:1252-1257.

12. Pectasides D, Aravantinos G, Fountzilas G, Kalofonos C, Efstathiou E, Karina M, Pavlidis N, Farmakis D, Economopoulos T, Dimopoulos MA: Brain metastases from epithelial ovarian cancer. the Hellenic Cooperative Oncology Group (HeCOG) experience and review of the literature. Anticancer Res 2005, 25:3553-3558.

13. Miraglia S, Godfrey W, Yin AH, Atkins K, Warnke R, Holden JT, Bray RA, Waller EK, Buck DW: A novel five-transmembrane hematopoietic stem cell antigen: isolation, characterization, and molecular cloning. Blood 1997, 90:5013-5021

14. Baba T, Convery PA, Matsumura N, Whitaker RS, Kondoh E, Perry T, Huang Z Bentley RC, Mori S, Fujii S, Marks JR, Berchuck A, Murphy SK: Epigenetic regulation of CD133 and tumorigenicity of CD133+ ovarian cancer cells. Oncogene 2009, 28:209-218.

15. Curley MD, Therrien VA, Cummings $C L$, Sergent PA, Koulouris CR, Friel AM, Roberts DJ, Seiden MV, Scadden DT, Rueda BR, Foster R: CD133 expression defines a tumor initiating cell population in primary human ovarian cancer. Stem Cells 2009, 27:2875-2883.

16. Zhang S, Balch C, Chan MW, Lai HC, Matei D, Schilder JM, Yan PS, Huang TH, Nephew KP: Identification and characterization of ovarian 
cancer-initiating cells from primary human tumors. Cancer Res 2008, 68:4311-4320

17. Zhang J, Guo X, Chang DY, Rosen DG, Mercado-Uribe I, Liu J: CD133 expression associated with poor prognosis in ovarian cancer. Mod Pathol 2012, 25:456-464.

18. Cheng JX, Liu BL, Zhang X: How powerful is CD133 as a cancer stem cell marker in brain tumors? Cancer Treat Rev 2009, 35:403-408.

19. Ferrandina G, Martinelli E, Petrillo M, Prisco MG, Zannoni G, Sioletic S, Scambia G: CD133 antigen expression in ovarian cancer. BMC Cancer 2009, 9:221.

20. Liao $Y$, Hu X, Huang $X$, He C: Quantitative analyses of CD133 expression facilitate researches on tumor stem cells. Biol Pharm Bull 2010, 33:738-742

21. Zeppernick F, Ahmadi R, Campos B, Dictus C, Helmke BM, Becker N, Lichter P, Unterberg A, Radlwimmer B, Herold-Mende CC: Stem cell marker CD133 affects clinical outcome in glioma patients. Clin Cancer Res 2008, 14:123-129.

22. Bristow RE, Tomacruz RS, Armstrong DK, Trimble EL, Montz FJ: Survival effect of maximal cytoreductive surgery for advanced ovarian carcinoma during the platinum era: a meta-analysis. J Clin Oncol 2002, 20:1248-1259.

23. Elattar A, Bryant A, Winter-Roach BA, Hatem M, Naik R: Optimal primary surgical treatment for advanced epithelial ovarian cancer. Cochrane Database Syst Rev 2011, 10, CD007565

24. Mizrak D, Brittan M, Alison M: CD133: molecule of the moment. J Pathol 2008, 214:3-9

25. Zhang SS, Han ZP, Jing YY, Tao SF, Li TJ, Wang H, Wang Y, Li R, Yang $Y$, Zhao X, Xu XD, Yu ED, Rui YC, Liu HJ, Zhang L, Wei LX: CD133(+)CXCR4(+) colon cancer cells exhibit metastatic potential and predict poor prognosis of patients. BMC Med 2012, 10:85.

26. Hermann PC, Huber SL, Herrler T, Aicher A, Ellwart JW, Guba M, Bruns CJ, Heeschen C: Distinct populations of cancer stem cells determine tumor growth and metastatic activity in human pancreatic cancer. Cell Stem Cell 2007, 1:313-323.

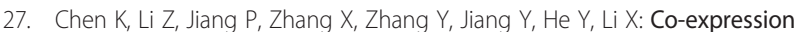
of CD133, CD44v6 and human tissue factor is associated with metastasis and poor prognosis in pancreatic carcinoma. Oncol Rep 2014, 32:755-763.

28. Shmelkov SV, Butler JM, Hooper AT, Hormigo A, Kushner J, Milde T, St Clair R, Baljevic M, White I, Jin DK, Chadburn A, Murphy AJ, Valenzuela DM, Gale NW, Thurston G, Yancopoulos GD, D'Angelica M, Kemeny N, Lyden D, Rafii S: CD133 expression is not restricted to stem cells, and both CD133+ and CD133- metastatic colon cancer cells initiate tumors. J Clin Invest 2008, 118:2111-2120.

29. Choijamts B, Jimi S, Kondo T, Naganuma Y, Matsumoto T, Kuroki M, Iwasaki $H$, Emoto M: CD133+ cancer stem cell-like cells derived from uterine carcinosarcoma (malignant mixed Mullerian tumor). Stem Cells 2011 29:1485-1495.

30. Bignotti E, Tassi RA, Calza S, Ravaggi A, Bandiera E, Rossi E, Donzelli C, Pasinetti B, Pecorelli S, Santin AD: Gene expression profile of ovarian serous papillary carcinomas: identification of metastasis-associated genes. Am J Obstet Gynecol 2007, 196:245. e241-211.

31. Alonso-Alconada L, Muinelo-Romay L, Madissoo K, Diaz-Lopez A, Krakstad C, Trovik J, Wik E, Hapangama D, Coenegrachts L, Cano A, Gil-Moreno A, Chiva L, Cueva J, Vieito M, Ortega E, Mariscal J, Colas E, Castellvi J, Cusido M, Dolcet X, Nijman HW, Bosse T, Green JA, Romano A, Reventos J, Lopez-Lopez R, Salvesen HB, Amant F, Matias-Guiu X, Moreno-Bueno G, et al: Molecular profiling of circulating tumor cells links plasticity to the metastatic process in endometrial cancer. Mol Cancer 2014, 13:223.

32. Pakneshan S, Safarpour D, Tavassoli F, Jabbari B: Brain metastasis from ovarian cancer: a systematic review. J Neurooncol 2014, 119:1-6.

33. Adler JR, Cox RS, Kaplan I, Martin DP: Stereotactic radiosurgical treatment of brain metastases. J Neurosurg 1992, 76:444-449.

34. Alexander E 3rd, Moriarty TM, Davis RB, Wen PY, Fine HA, Black PM, Kooy HM, Loeffler JS: Stereotactic radiosurgery for the definitive, noninvasive treatment of brain metastases. J Natl Cancer Inst 1995, 87:34-40.

35. Lee YK, Park NH, Kim JW, Song YS, Kang SB, Lee HP: Gamma-knife radiosurgery as an optimal treatment modality for brain metastases from epithelial ovarian cancer. Gynecol Oncol 2008, 108:505-509.

36. Brodsky AS, Fischer A, Miller DH, Vang S, MacLaughlan S, Wu HT, Yu J, Steinhoff M, Collins C, Smith PJ, Raphael BJ, Brard L: Expression profiling of primary and metastatic ovarian tumors reveals differences indicative of aggressive disease. PLoS One 2014, 9:e94476.
37. Matsumura N, Huang Z, Mori S, Baba T, Fujii S, Konishi I, Iversen ES, Berchuck A, Murphy SK: Epigenetic suppression of the TGF-beta pathway revealed by transcriptome profiling in ovarian cancer. Genome Res 2011, 21:74-82.

38. Yamamura S, Matsumura N, Mandai M, Huang Z, Oura T, Baba T, Hamanishi J, Yamaguchi K, Kang HS, Okamoto T, Abiko K, Mori S, Murphy SK, Konishi I: The activated transforming growth factor-beta signaling pathway in peritoneal metastases is a potential therapeutic target in ovarian cancer. Int J Cancer 2012, 130:20-28.

39. Baba T, Mori S, Matsumura N, Kariya M, Murphy SK, Kondoh E, Kusakari T, Kuroda H, Mandai M, Higuchi T, Takakura K, Fukuda MN, Fujii S: Trophinin is a potent prognostic marker of ovarian cancer involved in platinum sensitivity. Biochem Biophys Res Commun 2007, 360:363-369.

40. Hamanishi J, Mandai M, Abiko K, Matsumura N, Baba T, Yoshioka Y, Kosaka K, Konishi I: The comprehensive assessment of local immune status of ovarian cancer by the clustering of multiple immune factors. Clin Immunol 2011, 141:338-347.

41. Abiko K, Mandai M, Hamanishi J, Yoshioka Y, Matsumura N, Baba T, Yamaguchi K, Murakami R, Yamamoto A, Kharma B, Kosaka K, Konishi I: PD-L1 on tumor cells is induced in ascites and promotes peritoneal dissemination of ovarian cancer through CTL dysfunction. Clin Cancer Res 2013, 19:1363-1374.

42. Barnett JC, Bean SM, Whitaker RS, Kondoh E, Baba T, Fujii S, Marks JR, Dressman HK, Murphy SK, Berchuck A: Ovarian cancer tumor infiltrating T-regulatory (T(reg)) cells are associated with a metastatic phenotype. Gynecol Oncol 2010, 116:556-562

\section{doi:10.1186/1471-2407-14-829}

Cite this article as: Liu et al:: Platinum sensitivity and CD133 expression as risk and prognostic predictors of central nervous system metastases in patients with epithelial ovarian cancer. BMC Cancer 2014 14:829.

\section{Submit your next manuscript to BioMed Central and take full advantage of:}

- Convenient online submission

- Thorough peer review

- No space constraints or color figure charges

- Immediate publication on acceptance

- Inclusion in PubMed, CAS, Scopus and Google Scholar

- Research which is freely available for redistribution 